\title{
Thermoelastic Properties on Cu-Zn-Al Shape Memory Springs
}

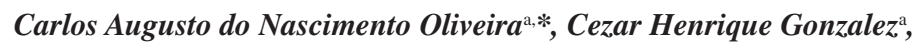 \\ Carlos José de Araújo ${ }^{\mathrm{b}}$, Oscar Olímpio de Araújo Filho ${ }^{\mathrm{a}}$, Severino Leopoldino Urtiga Filho ${ }^{\mathrm{a}}$ \\ ${ }^{a}$ Mechanical Engineering Department, Federal University of Pernambuco - UFPE, \\ Av. Acadêmico Hélio Ramos s/n, Cidade Universitária, CEP 50740-530 Recife, PE, Brazil \\ ${ }^{\mathrm{b}}$ Mechanical Engineering Department, Federal University de Campina Grande - UFCG, \\ Av. Aprígio Veloso, 882, CP 10069, CEP 58109-970 Campina Grande, PB, Brazil
}

Received: December 14, 2009; Revised: April 20, 2010

\begin{abstract}
This paper present a thermomechanical study of actuators in form of helical springs made from shape memory alloy wires that can work as actuator and/or as sensor. These abilities are due to the martensitic transformation. This transformation is a diffusionless phase transition that occurs by a cooperative atomic rearrange mechanism. In this work, helical spring actuators were manufactured from $\mathrm{Cu}-\mathrm{Zn}$ - $\mathrm{Al}$ shape memory alloy wires. The springs were submitted to constant tensile loads and thermal cycles. This procedure allows to determine thermoelastic properties of the shape memory springs. Thermomechanical properties were analyzed during 50 thermal cycles in the temperature range from 20 to $130{ }^{\circ} \mathrm{C}$. Results of variations in critical transformation temperatures, thermoelastic strain and thermal hysteresis are discussed based on defects rearrangement and martensitic transformation theory.
\end{abstract}

Keywords: shape memory effect, helical spring actuators, heat treatment and training process

\section{Introduction}

Shape memory alloys (SMA) have been used as actuators in various domains of knowledge due to recovery force, thermoelastic deformation and possibility to recover an initial shape when heated during reverse martensitic transformation ${ }^{1}$. In recent years, many researches have been developed to innovative engineering design using the actuation provided by the shape memory alloys ${ }^{2,3}$. These types of actuators are developed for special cases, as for example: reduction of cost and space, force application, simulation of the human movement (robotic) and surgery (biomedicine) $)^{4,5}$.

Helical spring actuators are very interesting for several technological applications. The reversible thermoelastic strain obtained with coil springs is larger in comparison with that one verified in wires. These last can reach about $5 \%$ of recovery strain in relation to its length. However, SMA spring can be deformed of 1 to 3 times its initial length. This fact is due to volume of material applied in the fabrication of spring (comparing wire and spring of equal lengths) and different stress states that act in spring.

In most research on this subject, SMA springs are submitted to a constant compression load. In the present work, a specific apparatus was developed to realize thermal cycling in SMA springs under constant tensile load. Temperature and displacement sensors, data acquisition system and a computer allow storing of the strain vs. temperature, critical transformation temperatures vs. number cycles and shear stress vs. transformation temperature curves. Thermoelastic properties (critical temperatures, thermal hysteresis, recovery strain, austenite and martensite elastic constant of the spring) and evolutions of hysteresis loops are determined with this apparatus. The aim of this paper is to analyze the variations of properties and loops during thermomechanical "training process" (or education process). This process is applied in SMA springs to obtain an adequate geometric form for each phase $($ cold $=$ martensitic phase and hot $=$ austenitic phase $)$. After training, a spontaneous shape change of the SMA is produced, in absence of mechanical loading, when it is heated or cooled (shape memorization $)^{6}$. This is one of the several ways to realize training process, for example: imposition of a load in the martensitic sample, after release of stress, heat and repeat cycle. During training process, important micromechanics occurs in the SMA, such as rearrangement of dislocations, reorientation of martensite variants, development of internal stresses, elimination of vacancies, reconfiguration of the order degree in austenite phase after quench and others ${ }^{7}$.

This work present result of the training process for four different loads in springs with $4.0 \mathrm{~mm}$ external diameter produced from $\mathrm{Cu}-\mathrm{Zn}-\mathrm{Al}$ SMA wire. The training procedure consists in the application of a constant tensile load on the SMA spring followed by the realization of 50 thermal cycles in the temperature range from 25 to $150{ }^{\circ} \mathrm{C}$. Results of thermoelastic properties and modification of hysteresis loops as a function of the number of cycles are discussed and news possibilities for technological applications of this configuration (under traction) of the SMA springs are presented.

\section{Experimental Procedure}

A commercial SMA wire with a nominal composition of $\mathrm{Cu}-25,3 \% \mathrm{Zn}-4,0 \% \mathrm{Al}$ wt.(\%) and $0.9 \mathrm{~mm}$ in diameter was used in this study. The wire was mechanically constrained on a cylindrical mandrel (screw) having a convenient geometric shape to originate the designed spring. In this alloys, shape memory effect is only verified in the spring after a betatisation heat treatment of. This treatment consist of a homogenization at $850{ }^{\circ} \mathrm{C}$ for 10 minutes followed by quench in water at $100{ }^{\circ} \mathrm{C}$, remaining in this temperature for 15 minutes. This annealing is used to eliminate excess of vacancies and to stabilize the 
configurational order of the austenitic phase. The main dimensions of the SMA spring obtained by this procedure are: external diameter of $4.0 \mathrm{~mm}$, length of $5.0 \mathrm{~mm}$ and four active coils.

Critical transformation temperatures of the wire were measured using a differential scanning calorimeter (DSC) Mettler 823 ${ }^{\mathrm{e}}$ model. For this test, three thermal cycles were realised in the temperature interval of range from 0 to 150 at $10{ }^{\circ} \mathrm{C} / \mathrm{min}$. Figure 1 present a special apparatus developed to determinate thermoelastic properties of the SMA springs under constant tensile stress. The load is applied on the sample through a pulley system. A programmable silicon oil bath is used to realize the heating and cooling cycles between -20 and $200{ }^{\circ} \mathrm{C}$. When on heating the spring contracts its size and when cooling the spring is extended. A linear variable displacement transducer (LVDT) and a thermocouple measure the strain and the temperature, respectively. The control and data acquisition system are connected to a computer.

The main equations utilized for the spring design are:

$$
\tau=K w \cdot \frac{8 F D}{\pi d^{3}}=K w \cdot \frac{8 F C}{\pi d^{2}}
$$

(Equation 1)

The Equation 2 is used to calculate the elastic constants of the SMA springs.

$$
k=\frac{F}{y}
$$

The main parameters of these equations are:

$\tau$ - shear stress, D - external diameter, $\mathrm{d}$ - diameter of wire, F - load applied, $\mathrm{C}$ - spring index $(\mathrm{C}=\mathrm{D} / \mathrm{d}), K w$ - Wahl factor (Equation 3) and $\mathrm{y}-$ spring deflection (Equation 4).

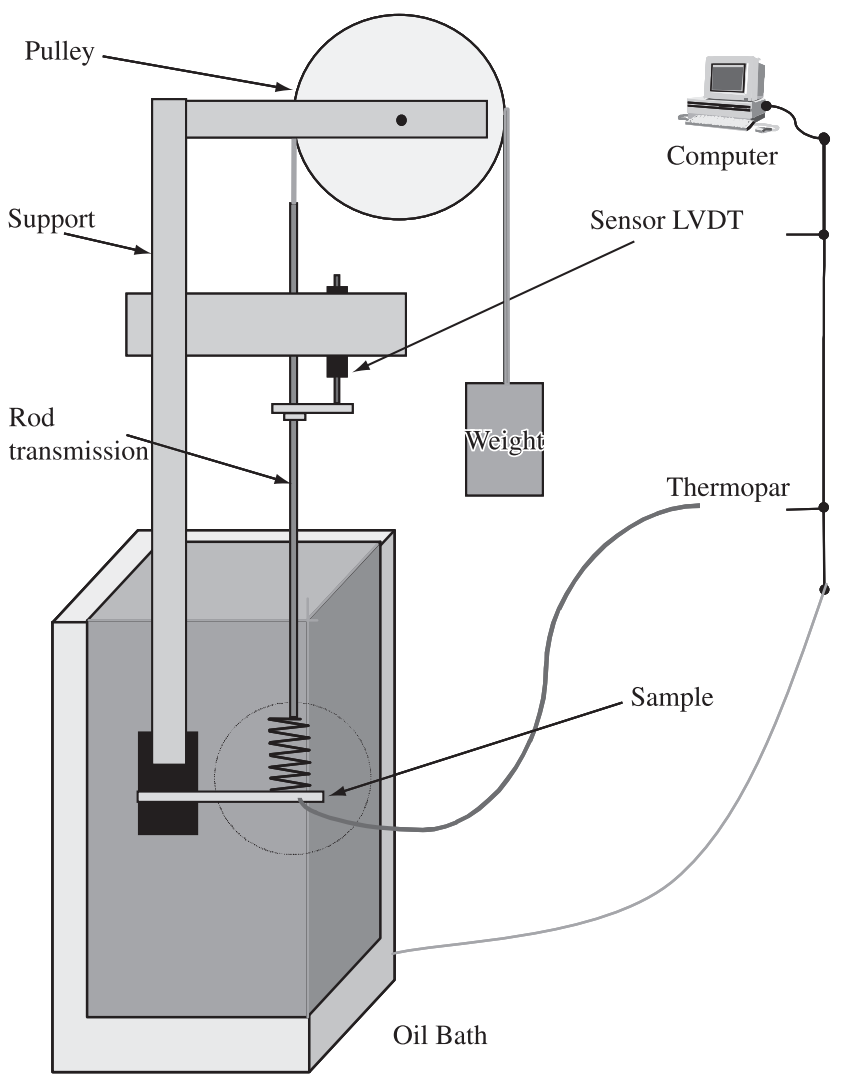

Figure 1. Schematic representation of the thermomechanical apparatus.

$$
\begin{gathered}
K_{W}=\frac{4 C-1}{4 C-4}+\frac{0,615}{C} \\
y=\frac{8 F D^{3} n}{d^{4} G}=\frac{8 F C^{3} n}{d G}
\end{gathered}
$$

In this work, samples were individually tested under constant tensile load originating shear stresses of 27,44, 55, 70, 83 and $111 \mathrm{MPa}$. For each applied load, the SMA spring was thermal cycled for 50 times between 20 and 150 at $10{ }^{\circ} \mathrm{C} / \mathrm{min}$ during heating and $3{ }^{\circ} \mathrm{C} / \mathrm{min}$ for cooling. Critical transformation temperatures, thermal hysteresis $\left(H_{t}=A_{50}-M_{50}\right)$, thermoelastic strain $\left(\varepsilon_{t}=\right.$ deformation at $\mathrm{A}_{\mathrm{s}}$ (austenite transformation star) temperature minus recovered deformation at $\mathrm{A}_{\mathrm{f}}$ (austenite transformation finish) temperature) are directly obtained from strain vs. temperature curves.

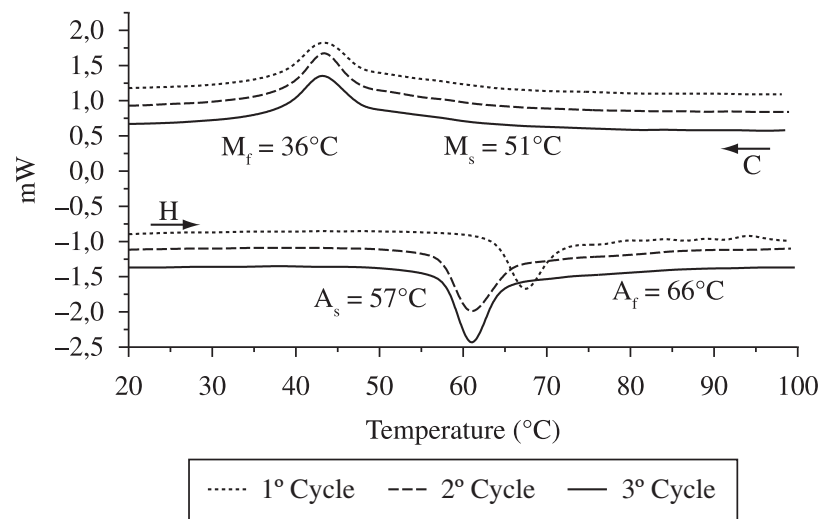

Figure 2. Calorimetric curves for a sample of the $\mathrm{Cu}-\mathrm{Zn}-\mathrm{Al}$ SMA wire.

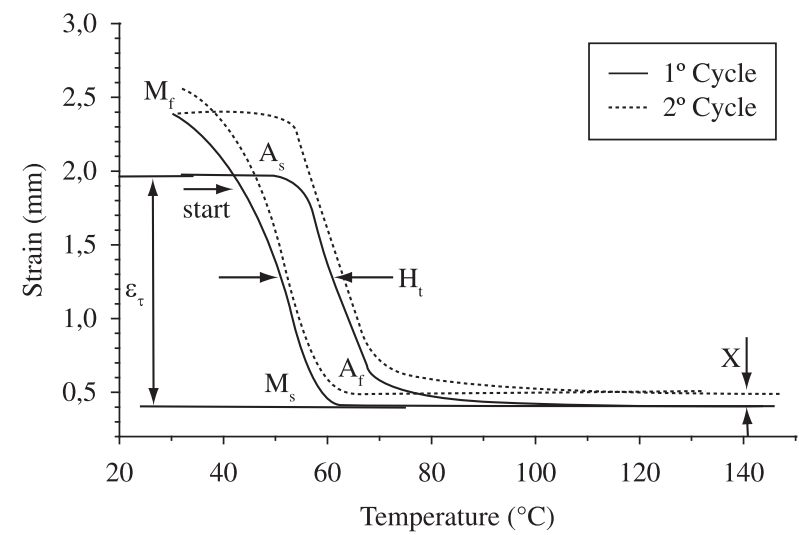

Figure 3. Representative strain vs. temperature curves obtained from a test of thermal cycling under constant load in the SMA springs.

Table 1. Critical temperatures and thermal hysteresis obtained from DSC for the $\mathrm{Cu}-\mathrm{Zn}-\mathrm{Al}$ SMA wire.

\begin{tabular}{cccc}
\hline Temperature $/ \mathrm{H}_{\mathrm{t}}$ & \multicolumn{3}{c}{ Cycles $\left({ }^{\circ} \mathrm{C}\right)$} \\
\cline { 2 - 4 } & $1^{\circ}$ & $2^{\circ}$ & $3^{\circ}$ \\
\hline $\mathrm{A}_{\mathrm{se}}$ & 70 & 63 & 57 \\
$\mathrm{~A}_{\mathrm{f}}$ & 78 & 73 & 66 \\
$\mathrm{M}_{\mathrm{s}}$ & 63 & 63 & 51 \\
$\mathrm{M}_{\mathrm{f}}$ & 48 & 49 & 36 \\
$\mathrm{H}_{\mathrm{t}}$ & 19 & 12 & 19 \\
\hline
\end{tabular}




\section{Result}

\subsection{Calorimetric characterization}

Samples of the SMA wire used in this study were heat treated in the same way of the springs (betatisation) and them analyzed by DSC. The aim was to determine the critical transformation temperatures without applied load. Figure 2 shows the calorimetric curves for three thermal cycles and Table 1 present critical temperatures for each cycle. In the first heating cycle, reverse transformation temperatures (austenitic phase - $\mathrm{A}_{\mathrm{s}}$ and $\left.\mathrm{A}_{\mathrm{f}}\right)$ are larger $\left(\approx 10^{\circ} \mathrm{C}\right)$ in comparison with the two subsequent cycles.

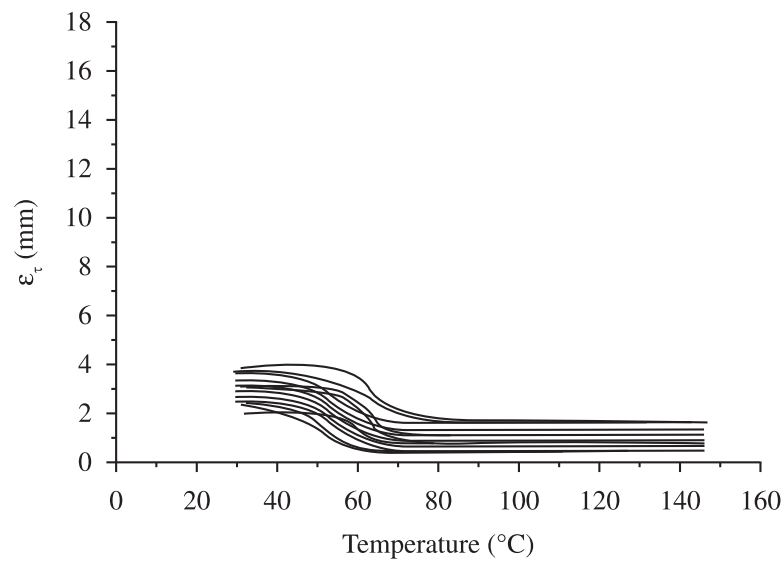

(a)

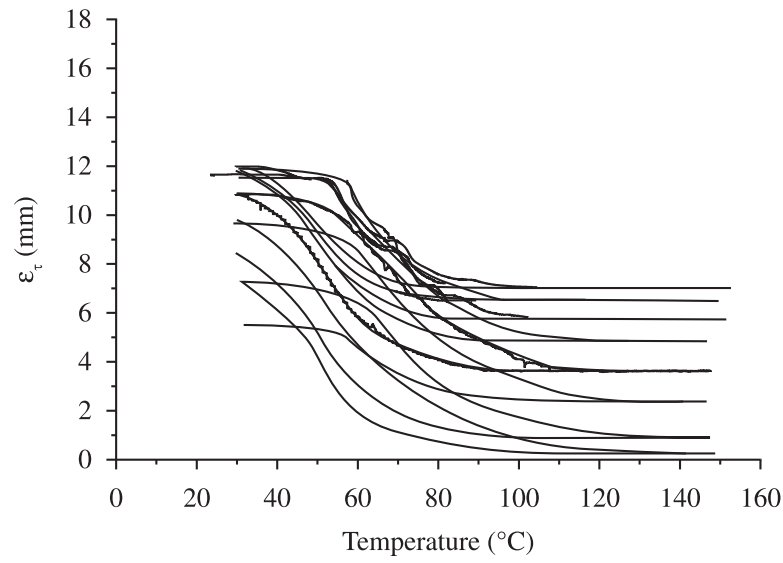

(c)

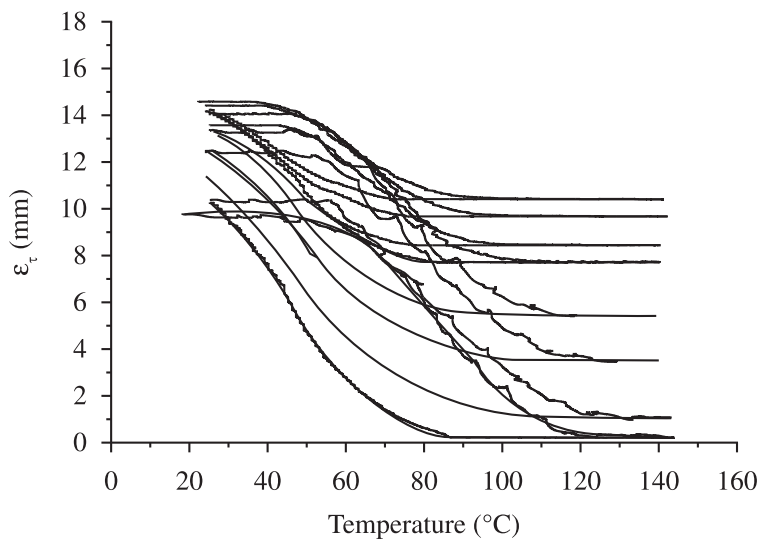

(e)
This effect occurs due to a martensitic stabilization process that can pinning the martensite-austenite interface by saturation of quenched-in vacancies and other mechanisms ${ }^{8-10}$. In the subsequent cycles, the critical temperatures and enthalpies become constant and repetitive ${ }^{11}$.

\subsection{Thermomechanical characterization}

Figure 3 show a strain-temperature curve obtained from tests performed with the apparatus described in the Figure 1. The main parameters that can be determined are: critical transformation temperatures under stress $\left(\mathrm{A}_{\mathrm{S}}, \mathrm{A}_{\mathrm{F}}, \mathrm{M}_{\mathrm{S}}\right.$ (martensitic transformation start)

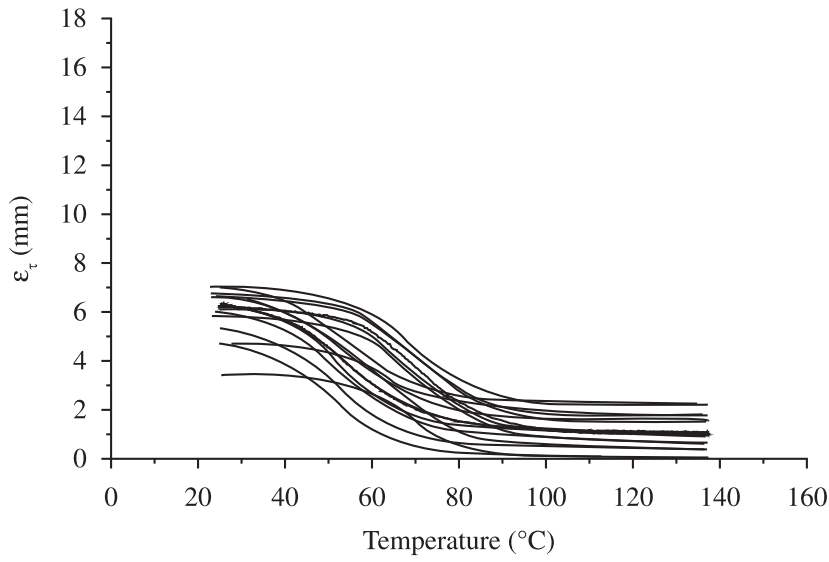

(b)

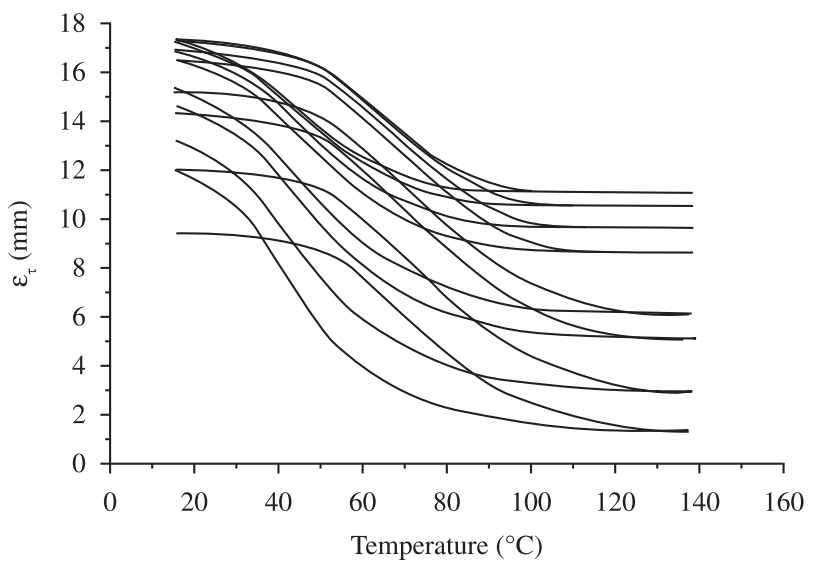

(d)

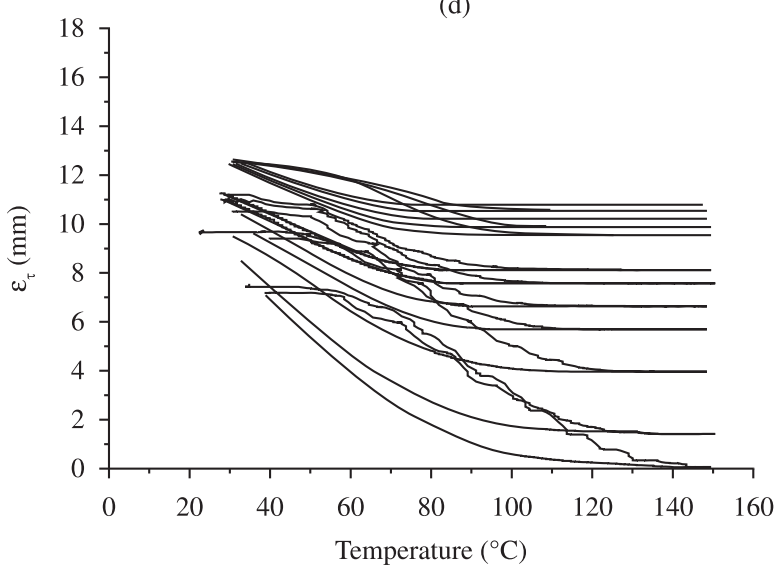

(f)

Figure 4. Strain-temperature loops for thermal cycling of the Cu-Zn-Al SMA springs. Tests for constant shear stress: a) $27 \mathrm{MPa}$, b) $44 \mathrm{MPa}$, c) $55 \mathrm{MPa}$, d) $70 \mathrm{MPa}$ e) $83 \mathrm{MPa}$ and f) $111 \mathrm{MPa}$. The loops represented are 1, 2, 5, 10, 20, 30, 40 e 50 for each load applied. 
and $\mathrm{M}_{\mathrm{F}}$ (martensitic transformation finish) that are determined using the tangent method), thermoelastic strain $\left(\varepsilon_{t}=\right.$ difference between the deflexions at low and high temperatures), thermal hysteresis $\left(\mathrm{H}_{t}\right)$, elastic constants of the martensitic and austenitic phase and vertical displacement of the hysteresis loops (X) (8). This displacement of loops is attributed to the accumulation of micro plastic deformation, but others factors also may contribute, as for example: martensitic stabilization process, martensite needles reorientation process.

Figure 4 show the strain - temperature loops for the cycles 1, 5, $10,20,30,40$ and 50 obtained for springs loaded with shear stresses of 27, 44, 55, 70, 83 and $111 \mathrm{MPa}$. Weight was applied in SMA spring at temperature below of $\mathrm{M}_{\mathrm{F}}$ where an initial deformation (deflection) is observed. After, the temperature control system is started for heating of spring and when the temperature reach $\mathrm{A}_{\mathrm{S}}$, the shape recovery process is initiated and progress until the $A_{F}$ temperature. During cooling, the thermoelastic deformation process begin when the temperature reach $\mathrm{M}_{\mathrm{S}}$ and is finalised at the $\mathrm{M}_{\mathrm{F}}$ temperature, corresponding to an expansion of the SMA spring.

The deformation produced and the evolution of hysteresis loops depend of applied load. The main contribution for the strain observed is due the thermoelastic martensite variant reorientation process. In this process, the martensite variants favored by the shear stress grow preferential variants while the others shrink. An excess of load can produce a plastic deformation in the SMA spring and reduce the recovery strain. These factors have a great influence on the behaviour of hysteresis loops during training, mainly in the twenty initials thermal cycles. After, the thermomechanical behaviour becomes practically stable.

During thermal cycles, the hysteresis loops are modified taking to variations in the critical transformation temperatures, thermal hysteresis, thermoelastic strains and slope of curves (for high loads). The inclinations observed in the strain vs. temperature curves for high loads tests are due to the fact that more energy is required to realize the transformation. Thus, the thermal amplitudes, defined as the difference between $\mathrm{A}_{\mathrm{F}}$ and $\mathrm{A}_{\mathrm{S}}$ during heating and the difference between $\mathrm{M}_{\mathrm{S}}$ and $\mathrm{M}_{\mathrm{F}}$ during cooling, become larger in comparison to small loads.

During thermal cycles, martensite variants reorientation and reconfiguration of pre-existent dislocations are active processes in the first cycles. Dislocations reconfiguration process promotes internal stress fields that facilitate the martensitic transformation. Critical temperatures and thermal hysteresis tend to decrease during the first twenty cycles. After these cycles, the new configuration of dislocations stabilizes the values of thermoelastic properties ${ }^{7}$.

Table 2 summarizes the deformation obtained in the initial loading and the thermoelastic strain $\left(\varepsilon_{t}\right)$ for each load in the cycles $1,5,10$, 15, 20, 30, 40 and 50. From Equation 4 and using the shear modulus for martensitic phase $(8.7 \mathrm{GPa})$, the deflection obtained in initial loading is very close to the one measured for 27,44 and $55 \mathrm{MPa}$.

Table 2. Thermoelastic deformation for each shear stress applied for several cycles.

\begin{tabular}{|c|c|c|c|c|c|c|c|c|c|}
\hline \multicolumn{10}{|c|}{ Thermoelastic deformation (mm) } \\
\hline Cycles & Initial & 1 & 5 & 10 & 15 & 20 & 30 & 40 & 50 \\
\hline \multicolumn{10}{|c|}{ Spring $-4.0 \mathrm{~mm}$} \\
\hline $27 \mathrm{MPa}$ & 0.6 & 2.0 & 2.9 & 3.0 & 3.1 & 3.1 & 3.6 & 3.7 & 3.9 \\
\hline $44 \mathrm{MPa}$ & 1.7 & 5.2 & 7.2 & 7.2 & 7.2 & 7.0 & 6.2 & 5.0 & 4.6 \\
\hline $55 \mathrm{MPa}$ & 4.2 & 3.4 & 5.1 & 5.2 & 5.1 & 5.2 & 5.0 & 4.9 & 4.7 \\
\hline $70 \mathrm{MPa}$ & 4.6 & 9.4 & 8.8 & 7.9 & 7.0 & 6.6 & 5.1 & 4.6 & 4.2 \\
\hline $83 \mathrm{MPa}$ & 5.0 & 8.4 & 9.6 & 9.4 & 8.7 & 8.1 & 7.5 & 7.0 & 6.5 \\
\hline $111 \mathrm{MPa}$ & 8.2 & 6.6 & 6.1 & 4.0 & 4.0 & 3.4 & 3.0 & 2.4 & 2.0 \\
\hline
\end{tabular}

For the other applied loads, the values are not close. Probably for loads larger than $55 \mathrm{MPa}$, occurs plastic deformation processes. In the test for $27 \mathrm{MPa}$, the recovery strain increase after each cycle. For the following load (42 MPa), the strain reaches a maximum and then decreases progressively. The largest value of the thermoelastic strain obtained for this load was $4.6 \mathrm{~mm}$. For other loads, the strains reach larger maximum values but decrease progressively during thermal cycles. The dislocations induced by the load excess and accumulated during thermal cycles originated a mechanical hardening of the SMA spring. This hardening process stabilizes the martensite variants and degradates the thermoelastic properties.

Figure 5 show the evolution of $\mathrm{M}_{\mathrm{s}}$ temperatures during the fifty cycles. It was observed a progressive augmentation of $\mathrm{M}_{\mathrm{S}}$ for springs tested with shear stress of $44 \mathrm{MPa}$ and $55 \mathrm{MPa}$. For tests performed with larger loads, the tendency for the $\mathrm{M}_{\mathrm{S}}$ evolution is of decrease. Other important observation is that the $\mathrm{M}_{\mathrm{s}}$ temperature increase almost lineally with applied loading. This evolution presents a slope of $1.85^{\circ} \mathrm{C} / \mathrm{MPa}$, shown in the Figure 6 . This value is very close to the one found in the shape memory alloys literature (Clausius-Claperyron relationship) ${ }^{12}$. For stress above $83 \mathrm{MPa}$, this relationship is not more valid. Reduction of $\mathrm{M}_{\mathrm{s}}$ and deviation of the linearity in slope for larger loads reinforce the hypothesis that martensite transformation is hindered by the increase of dislocation density, resulting in the hardening mechanism ${ }^{13}$.

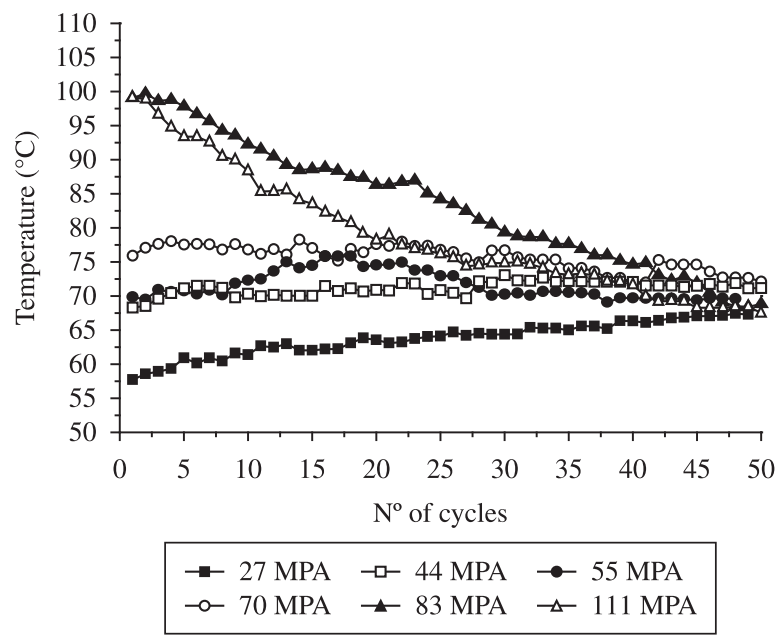

Figure 5. Ms temperature vs. number of thermal cycles for each applied shear stress in the $\mathrm{Cu}-\mathrm{Zn}-\mathrm{Al}$ SMA springs.

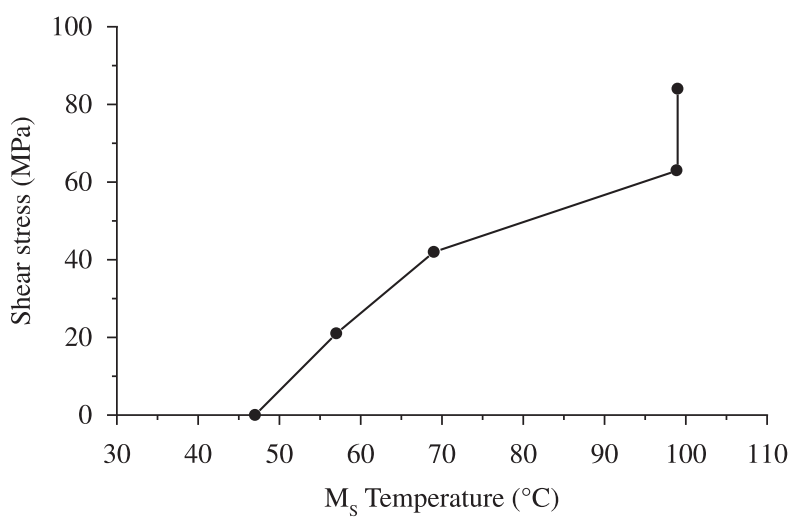

Figure 6. Ms temperature vs. shear stress for the Cu-Zn-Al SMA springs. 


\section{Conclusions}

In this work, $\mathrm{Cu}-\mathrm{Zn}$ - $\mathrm{Al}$ shape memory alloys springs were studied under constant tensile load and some thermomechanical properties were determined. During training process, the thermoelastic parameters of SMA springs are modified for the initial cycles. This evolution is due to the conjunction of various phenomena directly related amongst themselves, as martensite variants reorientation process, reconfiguration of dislocations, creation of internal stress fields, accumulation of plastic deformation and martensitic stabilisation processes. It was observed that after about 20 cycles the thermoelastic properties of the $\mathrm{Cu}-\mathrm{Zn}-\mathrm{Al} \mathrm{SMA}$ springs tend to stabilize. For applied loads lower than $55 \mathrm{MPa}$, the $\mathrm{M}_{\mathrm{s}}$ temperature increases during thermal cycling. In the case of loads higher than $55 \mathrm{MPa}$ an inverse behavior was observed and $\mathrm{M}_{\mathrm{S}}$ decrease progressively. In the first case, the applied load changes the thermoelastic properties slowly during cycling. In the second case, large loads induce excessive increase of the dislocation density causing stabilization of the shape memory effect. For SMA springs employed in this study $(4.0 \mathrm{~mm}$ in external diameter and 4 coils), the ideal training condition was obtained for a shear stress of $55 \mathrm{MPa}$ which present a thermoelastic strain of $4.6 \mathrm{~mm}$.

\section{Acknowledgements}

The authors acknowledge the Brazilian agencies: Coordenação de Aperfeiçoamento de Pessoal de Nível Superior (CAPES), Conselho Nacional de Desenvolvimento Científico e Tecnológico (CNPq) and Fundação de Amparo à Ciência e Tecnologia do Estado de Pernambuco (FACEPE) for financial support and scholarships to this research project.

\section{References}

1. Otsuka $\mathrm{K}$ and Wayman CM. Shape memory materials. Cambridge, UK: Cambridge University Press; 1998. p. 1-131.
2. Wu MH and McD. Schetky L. Industrial applications for shape memory alloys. In Proceedings of the International Conference on Shape Memory and Superelastic Technolgies; 2000; Pacific Grove, California. p. 171-182.

3. Laurentis KJ and Mavroidis C. Mechanical design of a shape memory alloy actuated prosthetic hand. Technology and Health Care. 2002; (10):91-106.

4. Machado LG and Savi MA. Medical applications of shape memory alloys. Brazilian Journal of Medical and Biological Research. 2003; 683-691.

5. Zhang C, Zee RH and Thoma PE. Development of Ni-Ti based shape memory alloys for actuation and control. In Proceedings of the 31st Intersociety Energy Conversion Engineering Conference - IECEC 96; 1996. p. 239-244.

6. De Araújo CJ, Silva E and Gonzalez CH. Thermal alarm using a shape memory alloy helical spring. In Proceedings of the 16th Brazilian Congress of Mechanical Engineering; 2001; Uberlândia - MG. p. 157-163.

7. Gonzalez CH, Araújo CJ, Quadros NF, Guénin G and Morin M. Study of martensitic stabilisation under stress in $\mathrm{Cu}-\mathrm{Al}-\mathrm{Be}$ shape memory alloy single crystal. Materials Science and Engineering. 2004; (378):253-256.

8. Gonzalez CH. Etude des comportements electro-thermomécaniques et de la stabilization martensitique d'alliages monocristallins à mémoire de forme base cuivre. Villerbonne, France : Institut National des Sciences Appliquées de Lyon ; 2002. p. 20-141.

9. Ahlers M. Stability of martensite in noble metal alloys. Materials Science and Engineering A. 2003; (349):120-131.

10. Zhang Y and Hornbogen E. Effects of plastic deformation of $\beta-\mathrm{Cu}-\mathrm{Zn}$-Al shape memory alloys on martensitic transformation cycles $\beta \leftrightarrow \alpha$. [S.1.]: Institute of Material Science, Ruhr-University; 1987. p. 401-405.

11. Perkins J and Muesing W E. Martensitic transformation cycling effects in Cu-Zn-Al shape memory alloys. [S.1.]: American Society for Metals and The Metallurgical Society of AIME; 1983. p. 33-36.

12. Otsuka K and Shimizu K. Pseudoelasticity and shape memory effects in alloys. International Metals Reviews. 1986; 31(3):93-114.

13. Oliveira CAN. Caracterização termoelástica de atuadores helicoidais da liga Cu-Zn-Al com memória de forma. [Dissertação de Mestrado]. Pernambuco: Universidade Federal de Pernambuco; 2007. 